\title{
Voracity and Growth Reconsidered
}

\author{
Holger Strulik* \\ Leibniz Universität Hannover, Discussion Paper No. 401 \\ ISSN 0949-9962
}

June 2008

\begin{abstract}
This article investigates economic performance when enforceable property rights are missing and subsistence needs matter. It shows that if per capita income is sufficiently high, a windfall gain in productivity triggers behavior that leads to higher growth (the normal reaction). The same shock can produce voracious behavior and lower growth when faced by poor economic agents, in particular when their productivity is low and their society is largely fractionalized. This leads to a re-assessment of the voracity effect. Economic and social performance depends no longer on character traits (the assumed curvature of the utility function) as assumed in the earlier literature. Instead, the initial degree of development, the state of technology, and the make up of society are decisive. An extension towards a two-sector economy shows that conditions for an active informal sector of low productivity are much less restrictive than originally thought.

Keywords: economic growth, property rights, common pool resources, voracity, fractionalization.

JEL: O11, O13, D74, P48.
\end{abstract}

\footnotetext{
${ }^{*}$ University of Hannover, Department of Economics, Koenigsworther Platz 1, 30167 Hannover, Germany, email: strulik@vwl.uni-hannover.de. I would like to thank participants of the SURED 2008 conference, of seminars at Copenhagen Business School and at the University of Hannover, Carl-Johan Dalgaard, Pietro Peretto, and, in particular, Karl Dietrich for useful comments.
} 


\section{INTRODUCTION}

A large empirical literature documents that economic performance suffers when institutions are weak and property rights are poorly protected. How the competition of powerful, output appropriating groups feeds back to economic growth was theoretically analyzed in a popular and influential article by Lane and Tornell (1996). They proposed to investigates appropriation behavior as a common pool resource game taking place within the framework of an $A k$ growth model. By now their model has been developed further in various directions and entered economic textbooks. ${ }^{1}$

One aspect that is emphasized by Lane and Tornell and the related literature is the so called voracity effect. Voracity means that the appropriating agents "overreact" to a positive productivity shock (or terms of trade improvement) such that the triggered increase in the speed of appropriation exceeds the gain in productivity. As a consequence growth declines after an event that would lead to higher growth under "normal" circumstances, i.e. if property rights were protected. Although thus defined voracious behavior is probably not the most natural reaction to economic shocks, Lane and Tornell $(1996,1999)$ have shown that voracity is indeed an observable phenomenon in the recent history of several developing countries.

Unfortunately, the modelling of the voracity effect - as it has been established in the literature so far - entails undesirable "side-effects". For example, the model predicts that countries of high productivity (where productivity exceeds time preference, $A>n \rho$ in the notation used below) shrink at a constant rate, whereas otherwise identical countries of low productivity (where $A<n \rho$ ) grow at a positive rate. In fact, for countries of low productivity, voracity should be a desirable feature according to the so far available theory. If voracity occurs, it turns a previously negative rate of economic growth positive. Most naturally, we would probably expect that countries plagued by voracity are converging to stagnation. Stagnation, however, occurs independently of voracity only in the case of a knife-edge parameter constellation (when $A=\rho n$ ).

Besides these qualitative imperfections the so far available theory entails also a quantitative problem. It needs an implausibly high value for the elasticity of intertemporal substitution. If there are two or more competing groups in society, $\sigma$ has to be necessarily (not sufficiently)

\footnotetext{
${ }^{1}$ For empirical literature on property rights and growth see, for example, Acemoglu et al., 2001, Easterly and Levine, 2003, and Rodrik et al. (2004). For further developments of Lane and Tornell's approach see Tornell and Lane (1999), Lindner and Strulik (2004, 2008), Strulik (2008b), Mino (2006), and Long and Sorger (2006). A detailed textbook treatment can be found in Drazen (2000).
} 
larger than one for voracity to exist. While the empirical literature not always agrees with Hall (1988) that $\sigma$ is close zero, it is probably fair to say that there is consensus between quantitative macro- and empirical microeconomists that the elasticity of intertemporal substitution is rarely larger than one. ${ }^{2}$ In addition, several studies have shown that $\sigma$ is particularly low for poor individuals and increasing in wealth and consumption. ${ }^{3}$

The present article re-investigates Lane and Tornell's setup now assuming that there are subsistence needs so that preferences can be described by a Stone-Geary utility function. This implies that the elasticity of intertemporal substitution is no longer constant. It is zero at subsistence level and - in line with the empirical evidence - increasing in consumption (and thus indirectly in wealth). The comparatively small refinement of the original setup leads to quite drastic modifications of results and, in fact, towards a comprehensive re-assessment of the voracity effect.

It will be shown that in particular poor individuals are prone to voracious behavior in spite of their currently small rate of intertemporal substitution. In fact, economic performance and social behavior will be shown to be completely independent of the elasticity of intertemporal substitution. Other factors matter for voracious behavior and poor economic performance. Now, ceteris paribus, individuals are more likely to appropriate "too much", i.e. to generate the voracity effect, if they are living close to subsistence needs, if they discount the future heavily (for example, because they are living in a high mortality environment), if their society is largely fractionalized, and if their productivity is low anyway.

While voracity could be interpreted as personality-specific behavior according to the earlier literature (occurring for preferences with high enough $\sigma$ ), it becomes situation-specific behavior according to the new approach. Individuals with the same preferences behave normally, i.e. non-voraciously, when their income is sufficiently high, when they are populating an economy that is sufficiently productive, and when society is sufficiently little fractionalized. In that case the economy may even manage to grow at a positive rate. Growth, however, will in any case be lower than it could be if property rights were secure. It will also be affected by the degree of fractionalization, possibly in a non-linear way.

Moreover, voracity, is shown to be an "off-steady-state" phenomenon. If an economy is capable of long-run growth despite of voracity, then voracious behavior disappears when income gets

${ }^{2}$ See, for example, Lucas (1990), Campbell and Mankiw (1989), and Patterson and Peseran (1992).

${ }^{3}$ Attansio and Browning (1995), Ogaki et. al (1996), Atkeson and Ogaki (1997), and Guvenen (2006). 
high enough. On the other hand, if a voracious economy is not capable of long-run growth, it converges towards stagnation at subsistence level and voracity disappears as an observable phenomenon because there is no growth.

In order to derive these results conveniently, Section 2 starts with the simplest case assuming a logarithmic form of the utility function. Section 3 investigates the role of fractionalization for economic performance and Section 4 the voracity effect. In Section 5 I then show that results are indeed independent from the assumed curvature of the Stone-Geary utility function. Section 6 extends the model to the two-sector setup investigated in Tornell and Lane (1999). It is shown that conditions for existence of an informal sector in which productivity is inferior but property rights are secure are much more general than initially thought. A sufficient, not necessary condition is that productivity in the informal sector exceeds the rate of time preference. If productivity of the informal sector is not high enough, it depends on productivity of the formal sector whether the economy grows and the informal sector disappears asymptotically or whether the common access sector gets plundered completely and the economy stagnates, relying exclusively on produce of the informal sector.

\section{The Basic Model}

Consider a society consisting of $n$ groups of a measure [0,1] of individuals. A group is defined by the fact that its member cooperate with each other and compete with member of other groups. Property rights are not defined or not enforceable so that the economy's aggregate capital stock $k$ is considered as a common pool resource. Output is produced via a linear $A k$ production technology. With missing property rights, consumption of a group $i, i=1, \ldots, n$, denoted by $c_{i}$, equals its appropriation of output. In appropriating output members of a group cooperate with each other and compete with members of other groups. In this endeavor they follow a Markov strategy, $c_{i}(k)$. Let $A$ denote capital productivity net of depreciation. Thus, leftovers of output after appropriation - if there are any - define investment and the (common pool) capital stock evolves according to (1).

$$
\dot{k}=A k-\sum_{j=1}^{n} c_{j} .
$$

The objective of each group is to maximize the present value of utility derived from consumption, $\int_{0}^{\infty} u\left(c_{i}\right) \mathrm{e}^{-\rho t} \mathrm{~d} t$, where $u(\cdot)$ is an instantaneous utility function and $\rho$ denotes the time 
preference rate. So far, the model coincides with Lane and Tornell (1996). Lane and Tornell proceed by assuming an iso-elastic utility function.

Here, we instead assume that instantaneous utility is subject to subsistence consumption $\bar{c}$, i.e. it is of the Stone-Geary type, $u\left(c_{i}\right)=\log \left(c_{i}-\bar{c}\right)$ for $c>\bar{c}$ and $u\left(c_{i}\right)=-\infty$ otherwise. Because subsistence consumption prevails, the rate of intertemporal substitution, calculated as $\sigma_{s}=$ $1-\bar{c} / c_{i}$, is no longer constant but determined by the degree of economic development. It assumes a value of zero at subsistence level and converges towards one as income and consumption go to infinity. Summarizing, the objective of group $i$ can be stated as

$$
\max \int_{0}^{\infty} \log \left(c_{i}-\bar{c}\right) \cdot e^{-\rho t} \mathrm{~d} t
$$

Like Lane and Tornell we focus on symmetric equilibria. In the Appendix it is shown that consumption strategy (3) solves the maximization problem (1) and (2) for all $i=1, \ldots, n$.

$$
c_{i}(k)=\left(1-\frac{n \rho}{A}\right) \cdot \bar{c}+\rho k
$$

Plugging (3) into (1) and noting that per capita output is $y=A k$ we obtain the growth rate of output per capita $g \equiv \dot{y} / y=\dot{k} / k$ as in (4).

$$
g=A-n \rho-\frac{n(A-n \rho)}{A} \cdot \frac{\bar{c}}{k}
$$

Inspection of (4) reveals that there exists an equilibrium of stagnation at subsistence level $(c=\bar{c}, k=n \bar{c} / A)$. Because $\partial \dot{k} / \partial k=A-\rho n$, the equilibrium is stable if $A<n \rho$. Intuitively, if the return on capital per group $A / n$ is so small that it falls short of the time preference rate $\rho$, the incentive to invest is so low that groups follow an extensive appropriation strategy. With negative investment rates the economy converges towards stagnation. Again, the textbook case of secure property is embedded for $n=1$, i.e. when there is only one group in society. The following proposition summarizes the result.

PROPOSITION 1. The economy without property rights and subsistence needs grows at a positive rate if and only if $A>n \rho$. Ceteris paribus growth is more likely to be observed, if an economy displays high productivity, if individuals are equipped with a low rate of time preference, and if social fractionalization is low. Not growing economies stagnate at subsistence level. 
The results with respect to productivity $A$ and time preference rate $\rho$ are immediately intuitive. The result with respect to $n$ gets empirical support from Easterly and Levine (1997) and Alesina et al. (2004). Intuitively, if a society is highly fractionalized and property rights are absent, a higher share of the return of one group's investment (in terms of foregone consumption) is appropriated by members of other groups. Since (Markov strategy using) people realize this fact, it drives down their individual incentive to invest. While the gross return on capital is always $A$, without established property rights and $n$ groups appropriating output, the return appropriated by an investing groups is just $A / n$. In line with the familiar result from neoclassical growth theory, there will be growth only if the individual net rate of return $A / n$ exceeds the rate of time preference.

Observe from (3) that the consumption rate $c_{i} / k$ converges to $\rho$ for $k \rightarrow \infty$. This means that the current model converges towards the one of Tornell and Lane in the log-utility case if output and consumption are perpetually growing. Observe also from (3) that under subsistence needs $(\bar{c}>0)$ the consumption rate is increasing in $k$ if productivity is sufficiently low and the society is sufficiently fractionalized, i.e. for $\rho n>A$. In this case the rate of investment into capital, $1-c_{i} / k$, is negatively associated with the level of capital, a fact that renders stability of stagnation at subsistence level. As a consequence not all economies are equally suffering from missing property rights. Disincentives on investment are particularly severe if productivity is low and the society is fractionalized. If the society is sufficiently homogenous and the economy sufficiently productive, $A>\rho n$, it converges towards the growth path already obtained in the literature.

\section{Fractionalization vs. Polarization: Effects on Growth}

If $A / n>\rho$, positive growth is viable with absent property rights albeit its rate is lower than it could be if property right were secure. Furthermore, growth may depend on social fractionalization in a nonlinear way. If the growth rate indeed assumes an extremum for a particular $n$, it is a minimum, as confirmed by the following derivatives.

$$
\frac{\partial g}{\partial n}=-\frac{A-2 n \rho}{A} \cdot \frac{\bar{c}}{k}-\rho, \quad \frac{\partial g^{2}}{\partial n^{2}}=\frac{2 \rho}{A} \cdot \frac{\bar{c}}{k}>0
$$


If a minimum exists, it is then found at

$$
n=n_{\min } \equiv \frac{A}{2 \rho}\left(1+\rho \cdot \frac{k}{\bar{c}}\right)
$$

This result is interesting with respect to the polarization literature (Esteban and Ray, 1994). There it is argued that the potential for conflict is highest for polarized societies, consisting of only a few groups, so that that the incentive to deviate from cooperative behavior is invertedly ushaped in fractionalization. This hypothesis is supported empirically by Keefer and Knack (2002) who find a non-linear relationship between ethnic homogeneity and the security of property rights whereby the risk of expropriation is highest for intermediate values of ethnic fractionalization. Similar results have been found by Zak and Knack (2001) with respect to trust in economic transactions and by Montalvo and Reynal-Querol (2005) with respect to ethnic polarization, potential conflict, and civil wars.

Figure 1: Fractionalization and Economic Growth

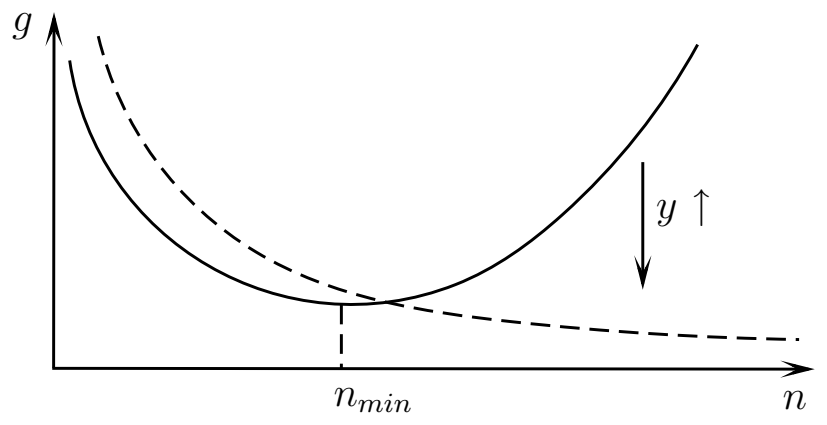

However plausible the polarization results sound, Easterly and Levine (1997) were not able to find a non-linear relationship between fractionalization and economic growth. Here we provide one explanation for the seemingly contradicting empirical findings. ${ }^{4}$ Inspection of (6) shows that with rising $k$ and thus per capita output $y$ the minimum at $n_{\min }$ is perpetually increasing and eventually becomes implausibly high to be assumed by any existing society. ${ }^{5}$ In this case the theory supports the observed monotonously negative relationship between $n$ and growth. Figure 1 illustrates the result. In other words, in search of non-linear effects across countries it may

${ }^{4}$ See Lindner and Strulik (2008) for an alternative explanation.

${ }^{5}$ With respect to ethnic or ethnolinguistic fractionalization, which is the focus of most empirical studies, the information that an $n_{\text {min }}$ exists where there are, say, 1000 groups is meaningless. 
be important to control for levels of aggregate poverty. A non-monotonous invertedly u-shaped relationship has - if at all - only a chance to be observed in a sample of poor countries with low aggregate productivity.

\section{The Voracity Effect}

Normally we expect that increasing productivity improves economic performances. Interestingly, Lane and Tornell have shown that a "voracity effect" may exist that produces just the opposite result. Increasing productivity leads to lower growth. In order to work out clearly the value added by the present paper it may help to begin with a short recap of Lane and Tornell's result. In the present paper's notation they obtain the following growth rate.

$$
g=(A-n \rho) \cdot \frac{\sigma}{n-\sigma(n-1)}
$$

where $\sigma$ is the (now constant) elasticity of intertemporal substitution. Obviously, voracity occurs, $\partial g / \partial A<0$, if the second term is negative, i.e. if $\sigma>n /(n-1)$. For a society consisting of two or more groups, voracity occurs if $\sigma$ is larger than one.

Besides the reliance on implausibly high rates of intertemporal substitution the voracity result entails some undesirable "side-effects". For example, voracity implies that a country with high productivity, $A>n \rho$, shrinks at a constant rate, whereas a country with low productivity, $A<n \rho$, grows at a positive rate. This is so because the second term in the above condition has to be negative for voracity to occur. In other words, voracity is particularly a problem for high productivity countries. For a country of low productivity, voracity should be a desirable feature. The appearance of voracity turns an otherwise negative growth rate positive. Most naturally, we would probably expect that countries plagued by voracity are converging to stagnation. Stagnation, however, occurs independently of voracity in case of a knife-edge parameter constellation (for $A=n \rho$ ).

Fortunately, all this can be "repaired". For the present model the elasticity of intertemporal substitution varies between zero and one depending on the stage of development, but it never exceeds one implying that Lane and Tornell's condition for voracity is never fulfilled. Nevertheless we can derive some empirically plausible conditions under which voracity occurs. For simplicity we stick to the log-form of utility first and show in the next section that the result 
holds indeed for any type of Stone-Geary utility function, implying that the mechanism that drives voracity is independent from $\sigma$.

Taking the derivatives of (4) w.r.t. $A$ we get (7), verifying that if growth assumes an extremum w.r.t. productivity, it is a minimum.

$$
\frac{\partial g}{\partial A}=1-\frac{n^{2} \rho}{A^{2}} \cdot \frac{\bar{c}}{k}, \quad \frac{\partial g^{2}}{\partial A^{2}}=\frac{2 n \rho}{A^{3}} \cdot \frac{\bar{c}}{k}>0
$$

If it exists, the growth minimizing productivity level is found at

$$
A=A_{\min } \equiv \sqrt{\frac{\rho \bar{c}}{k}} \cdot n .
$$

Inspection of (8) provides the following results.

Proposition 2. The growth minimizing productivity level depends positively on the rate of time preference, the level of subsistence needs, and the degree of social fractionalization. It also depends on the current state of the economy. The growth minimizing productivity level is decreasing in wealth $(k)$ and thus in per capita output $(y)$ of an economy.

COROllary 1. Ceteris paribus voracity is more likely to occur in fractionalized societies.

COROllary 2. Ceteris paribus voracity is a problem of low productivity countries.

COROLlary 3. If voracity occurs, it is attached to poverty. Ceteris paribus voracity becomes increasingly unlikely with rising per capita output, $A_{\min } \rightarrow 0$ for $k \rightarrow \infty$ (i.e. for $y \rightarrow \infty$ ).

For an intuition of the voracity effect we distinguish between a direct growth effect and an appropriation effect. The direct growth effect is always 1, an increase of productivity translates one-to-one into an increase of the gross return of capital. The appropriation effect leads each group to grab a higher share of output if productivity rises. From (3) we get the appropriation effect for a single group as $\partial c / \partial A=n \rho \bar{c} /\left(A^{2} k\right)$ and thus in total, for $n$ groups $n^{2} \rho \bar{c} /\left(A^{2} k\right)$. Voracity occurs if the appropriation effect exceeds the direct growth effect, i.e. if $n^{2} \rho \bar{c} /\left(A^{2} k\right)>1$, which is the condition for $\partial g / \partial A$ being negative in (7). As shown above, groups are more likely to appropriate "too much", i.e. to generate the voracity effect, if they are living close to subsistence needs, if they discount the future heavily (for example, because they are living in a high mortality environment), if their society is largely fractionalized, and if productivity is low anyway. 
Figure 2: The Voracity Effect

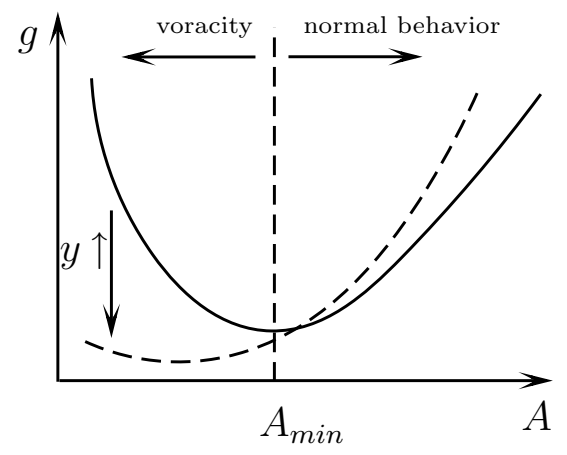

Figure 2 clarifies these results further. To the left of $A_{\text {min }}$, i.e. for low productivity we observe the voracity effect: a rise of productivity $A$ (or a windfall gain in terms of trade) leads to lower growth. But because $k$ is itself endogenous, voracity is a context-specific affair. As observed from (8), $A_{\min }$ is decreasing in $k$. Rising $k$ (or, equivalently, rising per capita output $A k$ ) shifts $A_{\min }$ to the left. Because voracity requires that $A<A_{\min }$ we find that, for any given productivity level, voracity is more likely to occur in poor countries.

Poverty itself, however, is endogenous, which renders voracity to be an "off-steady-state" phenomenon. To see this, consider first voracity occuring in a growing economy. Then, from (8), there exists a point of time where $k$ is large enough, i.e. average income is high enough, such that voracity disappears. Intuitively, current subsistence needs become less pressing so that the consumption rate does no longer overreact in response to productivity gains. Individuals realize that a positive productivity shock improves the future returns of capital and restrain their consumption in response.

Next, assume that a not growing economy is additionally plagued by voracity. In this case the economy converges towards subsistence. Compute $(\partial g / \partial A)_{\mid \bar{c}}=1-n \rho / A$ to verify that people in non-growing economies (i.e. where $A<n \rho$ ) are indeed voracious at subsistence level. At subsistence level, however, the economy stagnates. There is no growth anyway, a fact that renders (latent) voracity to be unobservable. The following proposition summarizes these insights.

Proposition 3. In the long-run, economies plagued by voracity do not grow. In the long-run, people in growing economies behave non-voraciously. 
The results lead towards a refined conceptualization of voracity. In Lane and Tornell's original articles voracity was character-contingent. It occurred for voracious people, i.e. when economic agents were somehow endowed with a too high $\sigma$. Here, voracity is context-specific. People living in an environment without enforceable property rights behave voraciously if productivity is so low that their economy converges towards stagnation in the long-run. People with the same preferences behave "normally" at higher levels of productivity. Of course "normal" behavior just means non-voracious according to the established definition. It does not mean a dictionary-proof opposite of voracious, which could be "moderate" or "cooperative". Non-voracious, competitive groups still consume too much and invest too little vis a vis the first-best, cooperative solution (see Lindner and Strulik, 2008).

In a broader interpretation the results provide also theoretical support for Friedman's (2005) claim that economic growth helps to sustain basic moral values. While Friedman's argument emphasizes the people's sense of getting ahead in retrospect, the current theory is forward looking. People behave voraciously only if they live in an environment where they do not expect enhanced future growth after a positive shock (low productivity, high fractionalization and mortality). On the other hand, if they expect to get ahead after a positive shock, in the sense of viability of long-run growth, they are predicted to behave non-voraciously.

The discussion has shown that stagnation at subsistence level is a global phenomenon, i.e. it will always happen if productivity and the degree of fractionalization do not support growth without property rights. Voracity, on the other hand is a local phenomenon, happening close to subsistence. Thus the model is compatible with the following scenario. At the beginning there was only one appropriating group, the colonial occupying force. Let's assume $A>\rho$ so that the economy was growing. At some moment in history the colonial power left and suddenly there were many (ethnic) groups starting to appropriate output. Output was still relatively high during this (post-colonial) period but the society was sufficiently fractionalized so that the economy could not grow without secure property rights, i.e. $A<n \rho$. Economic growth began to decline. During this period voracious behavior was not yet an issue. Productivity gains would have made the country better off. Yet, at one point of time during the transition towards stagnation, $k$ became small enough and poverty got severe enough so that people "became voracious". Windfall gains of productivity (or of terms of trade) now worsened the problem and lead to faster convergence towards subsistence. If we imagine that this story applies roughly to 
many Sub-Saharan African countries (and perhaps some Latin American countries as well) and

that entry into the "voracious period" occurred roughly in the 1970's, it helps to explain the combined evidence on external shocks and growth performance compiled by Lane and Tornell (1996, 1999) and Rodrik (1999).

\section{The General Case}

It remains to be shown that the results are independent from the log-utility form. In order to prove robustness of the voracity results for a general class of Stone-Geary utility functions we replace (2) by the objective

$$
\max \int_{0}^{\infty} \frac{\sigma}{\sigma-1}\left(c_{i}-\bar{c}\right)^{(\sigma-1) / \sigma} \cdot e^{-\rho t} \mathrm{~d} t
$$

In the Appendix it is shown that maximizing (9) subject to (1) is solved by the following Markovian consumption strategy.

$$
c_{i}=\frac{\sigma}{n-\sigma(n-1)} \cdot\left\{\left(1-\frac{n \rho}{A}\right) \cdot \bar{c}+\left[A \frac{(1-\sigma)}{\sigma}+\rho\right] \cdot k\right\} .
$$

For $\sigma=1$ the solution collapses to the one obtained for the simple model. Note also that the (interior) solution obtained by Tornell and Lane (1996) is embedded, which can be seen by setting $\bar{c}=0$. For positive $\bar{c}$ the elasticity of intertemporal substitution is, as before, not constant but reaches from zero at subsistence level to $\sigma$ for $c_{i} \rightarrow \infty$. The parameter $\sigma$ can thus be understood as the ultimate elasticity of intertemporal substitution.

Inserting the solution into the state equation, $\dot{k}=A k-n c_{i}$ provides the equilibrium growth rate $(11)$.

$$
g=A-\frac{\sigma n}{n-\sigma(n-1)} \cdot\left\{\left(1-\frac{n \rho}{A k}\right) \cdot \bar{c}+\left[A \frac{(1-\sigma)}{\sigma}+\rho\right]\right\} .
$$

In order to inspect the voracity effect we take the derivative with respect to $A$.

$$
\frac{\partial g}{\partial A}=1-\frac{\sigma n}{n-\sigma(n-1)}\left(\frac{n \rho \bar{c}}{A^{2} k}\right)-\frac{(1-\sigma) n}{n-\sigma(n-1)}=: f(\sigma)
$$

For the following discussion it is useful to conceptualize the derivative of the growth rate w.r.t. productivity as a function of the ultimate rate of intertemporal substitution $f(\sigma)$. In particular, note that $f(0)=0$. After some algebraic transformations we can write the derivative $f^{\prime}(\sigma)$ as 
$(13)$

$$
f^{\prime}(\sigma)=\frac{n}{[n-\sigma(n-1)]^{2}} \cdot\left\{1-\frac{n^{2} \rho \bar{c}}{A^{2} k}\right\}
$$

The first term is always positive so that the sign of $f^{\prime}(\sigma)$ is determined by the sign of the term in curly brackets. This term, however, is independent of $\sigma$. Thus, recalling that for the lowest conceivable elasticity of $\sigma=0, f(0)=0$, we have $f(\sigma)<0$ for all $\sigma>0$ if the term in curly brackets is negative. In this case we observe voracity. Otherwise, we get the normal reaction. Formally, $\partial g / \partial A=f(\sigma)>0$ for $A>\sqrt{\rho \bar{c} / k} \cdot n$ and $\partial g / \partial A=f(\sigma)<0$ for $A<\sqrt{\rho \bar{c} / k} \cdot n$. The implied minimum at $A_{\text {min }}=\sqrt{\rho \bar{c} / k} \cdot n$ coincides with the result for the log-utility case (8). The following proposition and corollary summarize the finding. Figure 3 provides a visual illustration.

Figure 2: Voracity and "Normal" Behavior in the General Case

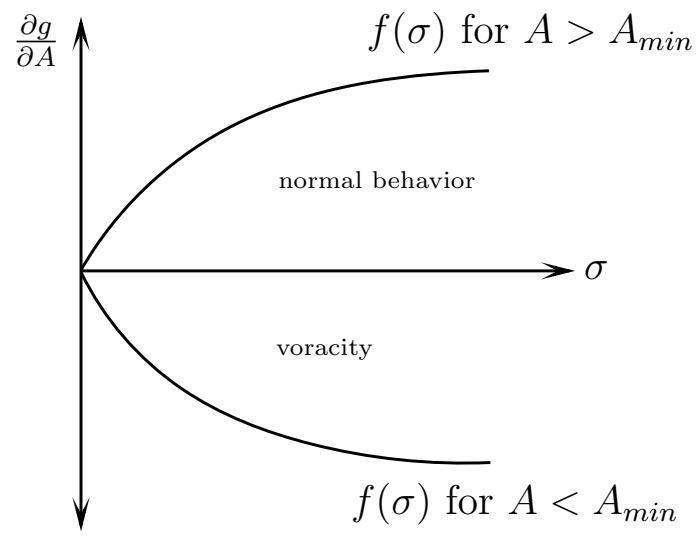

Proposition 4. For utility of the Stone-Geary type, the occurrence of voracity is independent from the ultimate elasticity of intertemporal substitution $\sigma$. The determinants of voracity are the same as for the special log-utility form (i.e. as stated in Section 4).

COROLlary 4. Starting from general Stone-Geary utility, the results found by Lane and Tornell (1996) can be understood as a consequence of the knife-edge assumption $\bar{c}=0$.

\section{The Two-Sector Model}

In an extension of the basic model Tornell and Lane (1999) consider a two-sector economy. The first sector (the formal sector) produces with a common-access asset $k$ while the second sector (the informal sector, the shadow economy) produces with a closed-access asset. The 
asset stock of members of group $i$ is denoted by $b_{i}$. Both sectors operate linear technologies and productivity of the first sector $(A)$ is higher than that of the second sector $(B) .{ }^{6}$ Let $r_{i}$ denote group $i$ 's appropriation of output of the common-access sector. There are two crucial differences with respect to the one-sector model. Appropriation from the first sector can be used for investment into the closed-access sector and even if the common-access resource disappears due to heavy appropriation, the economy may be viable in the long-run, relying exclusively on produce of the informal sector. Summarizing, the evolution of stocks is given by

$$
\begin{aligned}
\dot{k} & =A k-\sum_{i=1}^{n} r_{i}, \\
\dot{b}_{i} & =B b_{i}+r_{i}-c_{i}, \quad i=1, \ldots, n .
\end{aligned}
$$

To begin with, a brief recap of the central result from Tornell and Lane (1999) could again be helpful. Assuming a constant rate of intertemporal substitution $\sigma$ it is shown that an interior equilibrium with an active informal sector exists if (in the present paper's notation)

$$
n \leq \tilde{n} \equiv \frac{A-\sigma(B-\rho)}{B-\sigma(B-\rho)} \quad \text { and } B>\sigma(B-\rho)
$$

With contrast to the one-sector model, criticism and "repair" does now not so much focus on the equilibrium strategies but on the condition for existence of the equilibrium. Why should the existence of an informal sector depend on the degree of social fractionalization. And then, why should a shadow economy be less likely in largely fractionalized societies? Intuitively, one would expect that an informal sector exists as long as property rights in the formal sector are not protected and productivity in the informal sector is sufficiently high. The degree of fractionalization of society would then determine "only" the performance of such a two-sector economy. From a more general viewpoint, conditions (15) impose rather restrictive conditions for the existence of the object of investigation. Fortunately these shortcomings disappear after introducing subsistence needs into the utility function. Below I will show that a sufficient condition for existence of an informal sector is that $B>\rho$, i.e. the "natural" condition that productivity exceeds the rate of time preference. The condition is sufficient and, in fact, an informal sector can exist even if it is not fulfilled. These finding make the two-sector model and

\footnotetext{
${ }^{6}$ As Lane and Tornell we may distinguish between real productivity $\alpha$ and terms trade $p$, i.e. $A \equiv \alpha \cdot p$.
} 
its propositions about the shadow economy and voracity much more general than it might have been thought originally.

In order to derive the results in the most convenient way, we return to the log-utility case, i.e. groups are assumed to maximize (1) with respect to (14). In the Appendix it is shown that this problem is solved by the following appropriation and consumption strategies.

$$
\begin{aligned}
r_{i} & =\frac{A-B}{n-1} k \\
c_{i} & =\left(1-\frac{\rho}{B}\right) \bar{c}+\frac{(A-B) \rho}{(n-1) B} k+\rho b_{i} .
\end{aligned}
$$

Result (16a) will be responsible for the voracity effect. Since it coincides with the one found and discussed by Tornell and Lane, explanation can be brief. The condition requires that investing (or extracting) a unit of assets has the same net return in both sectors. In doing the calculation, groups take into account that if they appropriate one unit less of the common-access output, each of the other groups will appropriate $r_{i}^{\prime}(k)$ units more. Since there are $n-1$ other groups, net return on foregone appropriation from the common-access output is $A-(n-1) r_{i}^{\prime}(k)$, which has to be equal to $B$ in equilibrium, rendering thus $r_{i}(k)$ in (16a).

Inserting the strategies (16) into (14) we get the dynamics of the economic system (17).

$$
\begin{aligned}
\dot{k} / k & =\frac{n B-A}{n-1} \\
\dot{b}_{i} & =\frac{B-\rho}{B}\left(B b_{i}-\bar{c}+\frac{A-B}{n-1} k\right) .
\end{aligned}
$$

Taking derivatives of growth of the common asset (which equals growth of output of the formal sector) w.r.t. $A$ and $n$ provides the well known results on voracity and "power concentration".

$$
\frac{\partial g_{k}}{\partial A}=-\frac{1}{n-1}<0, \quad \frac{\partial g_{k}}{\partial n}=\frac{A-B}{(n-1)^{2}}>0
$$

Both results are readily explained using condition (16a) once more. Higher productivity in the common-access sector $(d A>0)$ leads groups to extract resources faster in order to equilibrate net returns with the given return in the informal sector $(B)$. Likewise if the number of groups increases $(d n>0)$, every single groups appropriates at slower speed in order to equilibrate sectoral net returns. This effect overcompensates the negative effect resulting from the fact that output is appropriated by more groups, i.e. $n /(n-1)$ is decreasing in $n$. The existence of a closed-access sector where property rights are protected modifies the results obtained for 
the one-sector economy quite drastically. In particular, it makes voracity a much more general phenomenon.

The results in (18) have been explored in detail by Lane and Tornell already. I thus now turn to two aspects that remained yet unexplored, the vanishing common-access sector and convergence towards subsistence. A major focus will be thereby on the persistence of the informal sector. Inspect (17a) to verify the following result.

Lemma 1. If $A / n>B$, then $g_{k}<0$, i.e. output of the common-access sector shrinks at a constant rate.

The condition is fulfilled if output per capita of the common-access sector is higher than that of the informal sector. To see this, recall that $b_{i}$ is the asset of group $i$ so that $B b_{i}$ is output of the informal sector per group. The measure of individuals in the economy was normalized to one. Because there are $n$ groups, each group consists of $1 / n$ individuals implying that $n B b_{i}$ is the output of the informal sector per capita. On a per capita basis a unit of assets thus produces output $A$ in the common-access sector and output $B n$ in the closed-access sector. This implies $A / n>B$ if we assume that the common-access sector is more productive on a per capita basis.

If $k$ vanishes, the evolution of the closed-access asset (17b) converges towards

$$
\dot{b}_{i}=\frac{B-\rho}{B}\left(B b_{i}-\bar{c}\right)
$$

Inspection shows that there exists an equilibrium at subsistence level where $B b_{i}=\bar{c}$. The equilibrium is stable if $\partial \dot{b}_{i} / \partial b_{i}=B-\rho<0$, i.e. if the time preference rate exceeds productivity of the informal sector. If the equilibrium is unstable (and $B b_{i}(0)>\bar{c}$ ), $b_{i}$ is perpetually growing. This provides the following result.

Proposition 5. If $A / n>B$, the formal sector vanishes in the long-run. In that case, the economy converges towards positive constant growth of the informal sector if $B>\rho$ and towards stagnation if $B<\rho$.

In others words, plundering of the common asset sector fuels growth of the closed asset sector if $B>\rho$, whereas otherwise time preference is too high and the "loot" from the first sector is not invested in the second sector but consumed. Convergence towards subsistence follows. Since the informal sector produces with private assets and under secure property rights, there is nothing special about the condition for growth. It is the standard textbook result requiring 
that the rate of return must exceed time preference. One example that would fit these dynamics (but not so well the original background story proposed by Lane and Tornell) is the plundering of the tropical rain forest and the creation of private (defendable) arable land.

However, I am not insisting here that $A / n>B$. If the condition is not fulfilled, $k$ grows at a positive rate. In that case, if $B>\rho$, production and growth in the informal sector is always larger than in the cases just discussed because the accumulation of $b_{i}$ is additionally fuelled by growing appropriation $r(k)$ from the common-access sector. Thus the informal sector is always active as long as it is sufficiently productive. The question, however, remains, whether it can get asymptotically unimportant. This would be the case, if $k$ grows continuously at a higher rate than $b_{i}$. To assess this question define private assets in excess of those necessary to produce subsistence needs, $\tilde{b}_{i} \equiv b_{i}-\bar{c} / B$. Then define the common-to-private asset ratio $z=k / \tilde{b}_{i}$. If there were a constant $z^{*}$ to which the economy converges, we would have a kind of balanced growth path along which the relative importance of common and private assets remains constant. The following proposition, proven in the Appendix, shows that such a path does not exist and establishes the asymptotic characteristics of sectoral development.

Proposition 6. Consider the case of $A / n<B$, i.e. long-run growth of the formal sector. There exists no positive and stable asset ratio $z^{*}=\left(k / \tilde{b}_{i}\right)^{*}$. If $B>\rho, \lim _{t \rightarrow \infty} z=0$, i.e. the common access sector disappears asymptotically. If $B<\rho, \lim _{t \rightarrow \infty} 1 / z=0$, i.e. the private access sector disappears asymptotically.

In other words, only if productivity of the informal sector is sufficiently low, $B<\rho$, the informal sector will disappear asymptotically if the formal sector is growing. Otherwise, for $B>$ $\rho$, both sectors grow but the relative importance of the formal sector disappears asymptotically. Note, again, that $B>\rho$ corresponds with the natural requirement for growth in the textbook model. Recalling that an informal sector is always active if $A / n>B$ we arrive at a conclusion on informal production and voracity that is more general than originally thought.

Proposition 7. Any economy starting above subsistence $\left(b_{i}>\bar{c} / B\right)$ consisting of a formal, common-access sector and a less productive informal sector with closed access will always produce in the low productivity sector if productivity in that sector exceeds time preference $(B>\rho)$. There will always be voracity unless the common access sector is completely plundered and thus the cause for voracity eliminated. 
Note that voracious behavior and production of the informal sector is independent from the make up of society. Social fractionalization determines, as derived above, which equilibrium the economy eventually assumes. Note also that Proposition 7 is utilizing a sufficient, not necessary condition since we have seen that if $B<\rho$ and $A / n>B$ the common access resource gets completely plundered and the economy stagnates relying exclusively on produce of the informal sector. Table 1 summarizes the results.

Table 1: Sectoral Performance with Absent Property Rights

\begin{tabular}{lll}
\hline$A>n B$ & common access sector disappears, & $B<\rho$ \\
& common access sector disappears, \\
growth of private access sector & stagnation of private access sector \\
\hline \multirow{2}{*}{$\begin{array}{l}\text { both sectors grow, } \\
\text { importance of common access }\end{array}$} & $\begin{array}{l}\text { both sectors grow, } \\
\text { importance of private access }\end{array}$ \\
\hline \hline
\end{tabular}

\section{Final Remarks}

In this article I have shown that the introduction of subsistence needs into an otherwise well known common pool game yields results that are probably harder to refute by the empirical evidence than those obtained in the earlier literature. In particular the findings become independent from the value that is assumed for the elasticity of intertemporal substitution. While low productivity and the degree of social fractionalization are the main drivers of economic performance, voracious behavior may occur situation-specific when output is low.

If productivity is high enough compared to time preference the economy may manage to escape from subsistence even when (enforceable) property rights are absent. Of course, also the growing economy suffers from competing groups in society as long as property rights remain to be unprotected. In case of the two-sector model it has been demonstrated that the introduction of subsistence needs relaxes the conditions for existence of an informal sector. In fact, an informal sector will - irrespective of the social makeup and of productivity in the formal sector - always exist if a natural condition is fulfilled, namely that the informal sector's marginal productivity exceeds the time preference rate.

The introduction of subsistence consumption in form of Stone-Geary utility has been proved to be a useful tool as well elsewhere in dynamic macroeconomics (see, for example, Easterly, 1994, Ben-David, 1998, Steger, 2000, and Strulik, 2008a). Technically it resolves problems 
arising from the (unrealistic) assumption that the elasticity of intertemporal substitution is constant and the implied inflexibility. At a deeper level the conceptualization of subsistence consumption as another "natural constant" appears to be somewhat incomplete. An extension of the present model towards an endogenous foundation of subsistence needs (for example along the lines proposed by Dalgaard and Strulik, 2007) is a promising and challenging task for future research. 


\section{Appendix}

Derivation of (3). The easiest way to solve the problem is to start with a transformation of variables. Let $\tilde{c}_{i}=c_{i}-\bar{c} \geq 0$ and $\tilde{k}=k-n \bar{c} / A \geq 0$, i.e. the deviation of consumption from subsistence level and the deviation of capital stock from subsistence capital stock. The maximization problem (1) and (2) can then be rewritten as

$$
\max _{\bar{c}_{i}} \int_{0}^{\infty} \log \tilde{c}_{i} \mathrm{e}^{-\rho t} \mathrm{~d} t, \quad \text { s.t. } \quad \dot{\tilde{k}}=A \tilde{k}-\sum_{i=1}^{n} \tilde{c}_{j}
$$

and $\tilde{k}(0) \geq 0$. The current value Hamiltonian reads

$$
H_{i}=\log \tilde{c}_{i}(k)+\lambda_{i}\left(A k-\sum_{j=1}^{n} \tilde{c}_{j}(k)\right) .
$$

It is straightforward to check that $H_{i}$ is concave in $\left(\tilde{k}, \tilde{c}_{i}\right)$. Equilibrium strategies are found where the first order conditions

$$
\begin{aligned}
\frac{1}{\tilde{c}_{i}} & =\lambda_{i}, \\
\lambda_{i}\left[A-\sum_{j \neq i}^{n} c_{j}^{\prime}(k)\right] & =\lambda_{i} \rho-\dot{\lambda}_{i},
\end{aligned}
$$

and the transversality condition $\lim _{t \rightarrow \infty} \lambda_{i}(t)\left[\tilde{k}(t)-\tilde{k}^{*}(t)\right] \mathrm{e}^{-\rho t} \geq 0$ hold for every group $i=1, \ldots, n$ and all feasible paths $\left(\tilde{k}(t), \tilde{c}_{i}(t)\right)$.

Applying symmetry, $\tilde{c}_{j}=\tilde{c}_{i}$ for all $j$ in (1) and (A.2), differentiating (A.1) with respect to time and substituting $\lambda_{i}$ and $\dot{\lambda}_{i}$ in (A.2) we get the equilibrium consumption strategy as defined by the following differential equation.

$$
{\tilde{c_{i}}}^{\prime}(\tilde{k})=\frac{(A-\rho) \tilde{c}_{i}}{A \tilde{k}-n \tilde{c}_{i}}
$$

It can be solved by the method of undetermined coefficients. Guess that $\tilde{c}_{i}=a \tilde{k}$ and thus ${\tilde{c_{i}}}^{\prime}=a$ and plug this into (A.3) to obtain $a=\rho$ and thus $\tilde{c}_{i}=\rho \tilde{k}$.

Next, insert the solution into the equation of motion $\dot{\tilde{k}}=A \tilde{k}-n \tilde{c}_{i}$, i.e. $\dot{\tilde{k}}=A \tilde{k}-n \rho \tilde{k}$. Solve the linear, homogenous differential equation to obtain

$$
\tilde{k}(t)=\tilde{k}(0) \mathrm{e}^{(A-n \rho) t} \quad \Rightarrow \quad \tilde{c}_{i}(t)=\rho \tilde{k}(0) \mathrm{e}^{(A-n \rho) t} .
$$

Since $\tilde{k}(t) \geq 0$ for all $t$, we can check for the Malinvaud transversality condition (Sydsaeter et al., 2005, 348-349). These are fulfilled if (i)

$$
\lim _{t \rightarrow \infty} \lambda_{i}(t) \mathrm{e}^{-\rho t}\left(0-\tilde{k}^{*}(t)\right) \geq 0
$$

and (ii) there exists a $t^{\prime}$ such that $\lambda(t) \geq 0$ for all $t>t^{\prime}$. Insert $\lambda_{i}(t)$ from (A.1) and $\tilde{c}_{i}=\rho \tilde{k}$ to obtain

$$
\lim _{t \rightarrow \infty}-\frac{1}{\tilde{c}_{i}(t)} \tilde{k}(t) \mathrm{e}^{-\rho t}=\lim _{t \rightarrow \infty}\left(-\frac{1}{\rho} e^{-\rho t}\right)=0 .
$$

Thus (i) is fulfilled. Compute

$$
\lambda_{i}(t) \frac{1}{\tilde{c}_{i}(t)}=\frac{1}{\rho \tilde{k}(t)}=\frac{1}{\rho \tilde{k}_{0}} \mathrm{e}^{(n \rho-A) t} .
$$


Set $t^{\prime}=0$ to verify that $\lambda(t) \geq 0$ for all $t>t^{\prime}$ and to conclude that (ii) is fulfilled. Thus, the transversality condition is fulfilled. Finally re-transformate variables $\tilde{c}_{i}=\rho \tilde{k}=\rho k-\rho n \bar{c} / A$ and $c_{i}=\tilde{c}_{i}+\bar{c}$ to arrive at (3).

Derivation of (10). As in the simple case we begin with a transformation of variables $\tilde{c}_{i}=c_{i}-\bar{c} \geq 0$ and $\tilde{k}=k-n \bar{c} / A \geq 0$ such that the Hamiltonian associated with problem (1) and (9) is given by.

$$
H=\frac{\sigma}{\sigma-1} \tilde{c}_{i}^{(\sigma-1) / \sigma}+\lambda_{i}\left[A \tilde{k}-\sum_{j=1}^{n} \tilde{c}_{j}(k)\right] .
$$

The first order condition with respect to $\tilde{c}_{i}$ is

$$
\tilde{c}_{i}^{-1 / \sigma}=\lambda_{i}
$$

Everything else is as before, in the simple case. Applying symmetry, $\tilde{c}_{j}=\tilde{c}_{i}$ for all $j$ in (1) and (A.2), differentiating (A.4) with respect to time and substituting $\lambda_{i}$ and $\dot{\lambda}_{i}$ in (A.6) we get the equilibrium consumption strategy as defined by the following differential equation.

$$
\tilde{c}_{i}^{\prime}(\tilde{k})=\frac{(A-\rho) \tilde{c}_{i}}{\frac{1}{\sigma} A \tilde{k}+\left(n-1-\frac{n}{\sigma}\right) \tilde{c}_{i}} .
$$

It can be solved by the method of undetermined coefficients. Guess again that $\tilde{c}_{i}=a \tilde{k}$ and thus ${\tilde{c_{i}}}^{\prime}=a$ and plug this into (A.7) to obtain

$$
a\left[\frac{1}{\sigma} A \tilde{k}+\left(n-1-\frac{n}{\sigma}\right) a \tilde{k}\right]=a \tilde{k}(A-\rho) .
$$

The non-trivial solution of (A.8) is

$$
a=\frac{\sigma}{n-\sigma(n-1)}\left[A \frac{1-\sigma}{\sigma}+\rho\right],
$$

which renders (10) in the text. The implied growth rate of $\tilde{k}=A-n \tilde{c}_{i} / k$ is

$$
\frac{\dot{\tilde{k}}}{\tilde{k}}=A-\frac{\sigma}{n-\sigma(n-1)}\left[A \frac{1-\sigma}{\sigma}+\rho\right]
$$

Since $\tilde{c}_{i}$ and $\tilde{k}$ grow at the same rate, the transversality condition simplifies to

$$
\left.\lim _{t \rightarrow \infty} \lambda(t)\left(0-\tilde{k}^{(} t\right)\right) e^{-\rho t}=\lim _{t \rightarrow \infty}\left(-\tilde{c}_{i}^{-1 / \sigma} \tilde{k}^{*}(t) e^{-\rho t}\right)=\lim _{t \rightarrow \infty}\left(-a \tilde{k}^{*}(t)^{-(1-\sigma) / \sigma} \mathrm{e}^{-\rho t}\right) \geq 0 .
$$

Together with (A.10) this requires that

$$
-\frac{1-\sigma}{\sigma}(A-\rho)\left[1-\frac{n \sigma}{n-\sigma(n-1)} \cdot \frac{(1-\sigma)}{\sigma}\right]<0 .
$$

It is readily verified that this is always true for $\sigma<1$. For $\sigma>1$ we need a restriction on parameters. Condition (A.11) holds true if either $n>\sigma /(\sigma-1)$ and $(\sigma-1) A-\sigma \rho<0$, or the opposite, i.e. $n<\sigma /(\sigma-1)$ and $(\sigma-1) A-\sigma \rho>0$.

Derivation of (16). Let's begin again with a retransformation of variables, $\tilde{c}_{i}=c_{i}-\bar{c} ; \tilde{b}_{i}=b_{i}-\bar{c} / B$. The Hamiltonian associated with the problem of maximizing (2) subject to (14) is given by

$$
H=\log \tilde{c}_{i}+\lambda_{i}\left[A k-\sum_{j=1}^{n} r_{j}(k)\right]+\mu_{i}\left[B \tilde{b}_{i}-\tilde{c}_{i}+r_{i}\right] .
$$


The first order conditions are

$$
\begin{aligned}
& \frac{1}{\tilde{c}_{i}}=\mu_{i} \\
& -\lambda_{i}+\mu_{i}=0 \\
& \lambda_{i}\left[A-\sum_{j \neq i}^{n} r_{j}^{\prime}(k)\right]=\lambda_{i} \rho-\dot{\lambda}_{i}, \\
& \mu_{i} B=\mu_{i} \rho-\dot{\mu}_{i} \Rightarrow-\dot{\mu}_{i} / \mu_{i}=B-\rho .
\end{aligned}
$$

for all groups $i$ where $\lambda_{i}$ denotes the shadow price of the common stock $k$ and $\mu_{i}$ is the shadow price of the private asset $\tilde{b}_{i}$. Because appropriation from the first sector can be transformed one-to-one into investment in the second sector, the shadow prices for both assets are equal, which manifests in (A.13b).

Applying symmetry, the first order conditions can be summarized as in (A.14).

$$
\begin{aligned}
r_{i}^{\prime}(k) & =\frac{A-B}{n-1} \\
\tilde{c}_{i}^{\prime} & =\frac{(B-\rho) \tilde{c}_{i}}{B \tilde{b}_{i}-\tilde{c}_{i}+r_{i}} .
\end{aligned}
$$

The linear differential equation (A.14a) can immediately be solved. The solution is (16a) in the text. And thus $\tilde{b}_{i}$ evolves according to

$$
\dot{\tilde{b}}=B \tilde{b}_{i}-\tilde{c}_{i}+\frac{A-B}{n-1} k
$$

To solve for $\tilde{c}_{i}$ suppose the solution has the form $\tilde{c}_{i}=a+d \tilde{b}_{i}$, where $a$ and $d$ are the coefficients to be determined. We then have

$$
d\left[B \tilde{b}_{i}+\left(a+d \tilde{b}_{i}\right)+r_{i}\right]=(B-\rho)\left(a+d \tilde{b}_{i}\right)
$$

Sorting terms.

$$
d \tilde{b}_{i}(\rho-d)=(B-\rho) a-d r_{i}+d a
$$

A non-trivial solution of this equation is $d=\rho$ and $a=\rho r_{i} / B$ and thus after insertion of (16a).

$$
\tilde{c}_{i}=\rho \tilde{b}_{i}+\frac{\rho}{B} \frac{A-B}{n-1} k .
$$

Re-retransformation of variables renders $(16 \mathrm{~b})$ in the text.

Proposition 6 (and check of transversality conditions). Consider first the case $A>n B$, i.e. the case of the vanishing common access sector; $\lim _{t \rightarrow \infty} k=0$.. Thus from (A.16) $\lim _{t \rightarrow \infty} \tilde{c}_{i}=\rho b_{i}$. And then from $\left.(\mathrm{A} .15) \lim _{t \rightarrow \infty}\left(\dot{\tilde{c}}_{i} / \tilde{c}_{i}\right)=\lim _{t \rightarrow \infty}\left(\dot{\tilde{b_{i}}} / \tilde{b}_{i}\right)\right)=B-\rho$. Using (A.13a) and (A.13b) the transversality condition with respect to $k$ simplifies to $\lim _{t \rightarrow \infty} \mathrm{e}^{-\rho t} \mathrm{e}^{-(B-\rho)} \cdot 0$, which is trivially fulfilled, and the transversality condition with respect to $\tilde{b}_{i}$ becomes $\lim _{t \rightarrow \infty} \mathrm{e}^{-\rho t} \cdot(-1 / \rho) \geq 0$, which is true.

In case of $A<n B$, the common access sector grows at a positive rate and $k(t)$ evolves according to

$$
k(t)=k_{0} \mathrm{e}^{\frac{n B-A}{n-1} t} .
$$

In order to discuss asymptotic properties in this case, it is convenient to define the asset ratio $z \equiv k / \tilde{b}_{i}$. Using (A.15) and (A.17), we see that $z$ grows at the following rate.

$$
\frac{\dot{z}}{z}=\frac{n B-A}{n-1}-(B-\rho)-\frac{A-B}{(n-1)} \frac{(B-\rho)}{B} \cdot z .
$$

Conclude that $z$ explodes when $(B-\rho)<0$. In case of $(B-\rho)>0$ there might exist a stable $z^{*}>0$ to which the economy converges. Consider $(B-\rho)>0$ and assume that such a $z^{*}$ exists. From (A.18), it 
would then be found where

$$
\frac{A-B}{(n-1)} \frac{(B-\rho)}{B} \cdot z^{*}=\frac{n B-A}{n-1}-(B-\rho) .
$$

Since we have assumed that $A>B$ and that $(B-\rho)>0$, the factor in front of $z^{*}$ at the left hand side is positive. Thus the right hand side has to be positive for a positive $z^{*}$ to exist. This requires

$$
n B-A>(n-1)(B-\rho) \Rightarrow(n-1) \rho>A-B .
$$

Since we have assumed that $A<n B$, this requires that

$$
(n-1) \rho>n B-B \Rightarrow \rho>B,
$$

which is a contradiction to the initial assumption that $(B-\rho)>0$. Consequently, there exists no positive stable $z^{*}$ and $z$ converges to zero for $(B-\rho)>0$. For inspection of the transversality conditions consider first the case where $(B-\rho)>0$ and $z$ vanishes. From (A.16), $\tilde{c}_{i} / \tilde{b}_{i}=\rho+(\rho / B) \cdot(A-B) /(n-1) \cdot z$, and thus $\lim _{t \rightarrow \infty} \tilde{c}_{i} / \tilde{b}_{i}=\rho$. Consumption and private assets grow at the same rate eventually. The transversality condition with respect to $\tilde{b}_{i}$ simplifies to $\lim _{t \rightarrow \infty} \mu(t) \mathrm{e}^{-\rho t}\left(0-\tilde{b}^{*}(t)\right)=(-1 / \rho) e^{-\rho t} \geq 0$, which is true. The transversality condition with respect to $k$ becomes $\lim _{t \rightarrow \infty} \lambda(t) e^{-\rho t}\left(0-k(t)^{*}\right)=$ $\lim _{t \rightarrow \infty}(-1 / \rho) \mathrm{e}^{-(B-\rho) t} \mathrm{e}^{-\rho t} \mathrm{e}^{\frac{n B-A}{n-1} t} \geq 0$. It requires that

$$
B>\frac{n B-A}{n-1} \Rightarrow n B-B>n B-A \Rightarrow A>B,
$$

which was the starting point of the whole analysis. Thus the transversality conditions are fulfilled.

The case $(B-\rho)<0$ is a mirror image of the case just discussed. Now $z$ goes to infinity in the long-run implying that $1 / z$ goes to zero, i.e. the private access sector vanishes asymptotically and $\tilde{c}_{i}$ grows at the rate of $k$ in the limit. Thus the transversality condition with respect to $k \operatorname{simplifies~to~} \lim _{t \rightarrow \infty}\left(-\mathrm{e}^{-\rho t}\right) \geq 0$, which is true. 


\section{References}

Acemoglu, D., Johnson, S., and Robinson, J.A., 2001, The colonial origins of comparative development: An empirical investigation, American Economic Review 91, 1369-1401.

Alesina, A., Devleeschauwer, A., Easterly, W., Kurlat, S. and Wacziarg, R., 2003, Fractionalization, Journal of Economic Growth 8, 155-194.

Atkeson, A. and Ogaki, M., 1996, Wealth-varying elasticity of substitution: Evidence from panel data and aggregate data, Journal of Monetary Economics 38, 507-537.

Attanasio, O. and Browning, M., 1995, Consumption over the life-cycle and over the the business cycle, American Economic Review 85, 1118-1137.

Ben-David, D., 1998, Convergence clubs and subsistence economies, Journal of Development Economics $55,155-171$.

Campbell, J.Y. and Mankiw, N.G., 1989, Consumption, income, and interest rates: reinterpreting the time series evidence, in: Blanchard, O., Fischer, S. (eds.), NBER Macroeconomics Annual, MIT Press.

Dalgaard, C.J. and Strulik, H., 2007, A bioeconomic foundation of the Malthusian equilibrium: body size and population size in the long-run,University of Hannover, Discussion Paper 373.

Drazen, A., 2000, Political Economy in Macroeconomics, Princeton University Press, Princeton.

Easterly, W., 1994, Economic stagnation, fixed factors, and policy thresholds, Journal of Monetary Economics 33, 525-557.

Easterly, W. and Levine, R., 1997, Africa's growth tragedy: Policies and ethnic divisions, Quarterly Journal of Economics 111, 1203-1250.

Easterly, W. and Levine, R., 2003, Tropics, germs, and crops: How endowments influence economic development, Journal of Monetary Economics 50, 3-39.

Esteban, J.-M. and Ray, D., 1994, On the measurement of polarization, Econometrica 62, 819-851.

Friedman, B.M., 2005, The Moral Consequences of Economic Growth, Random House, New York.

Guvenen, F., 2006, Reconciling conflicting evidence on the elasticity of intertemporal substitution: A macroeconomic perspective, Journal of Monetary Economics 53, 1451-1472.

Hall, R.E., 1988, Intertemporal substitution in consumption, Journal of Political Economiy 96, 330-357.

Keefer, P. and Knack, S., 2002, Polarization, politics, and property rights: Links between inequality and growth, Public Choice 111, 127-54.

Lane, P.R. and Tornell, A., 1996, Power, growth, and the voracity effect, Journal of Economic Growth 1, 213-241.

Lindner, I. Strulik, H., 2004, Why not Africa? - Growth and welfare effects of secure property rights, Public Choice 120, 143-167,

Lindner, I. and Strulik, H., 2008, Social fractionalization, endogenous appropriation norms, and economic development, Economica, forthcoming.

Long, N.V. and Sorger, G., 2006, Insecure property rights and growth: The role of appropriation costs, wealth effects, and heterogeneity, Economic Theory 28, 513-529.

Lucas, R.E., 1990, Supply-side economics: an analytical review, Oxford Economic Papers 42, 293-316.

Mino, K., 2006, Voracity vs. scale in a growing economy without secure property rights, Economics Letters 93, 278-284.

Montalvo, J.G. and Reynal-Querol, M., 2005, Ethnic polarization, potentail conflict, and civil wars, American Economic Review 95, 796-816.

Ogaki, M., Ostry, J.D., and Reinhart, C.M., 1996, Saving behavior in low- and middle-income developing economies, IMF Staff Papers 43, 38-71. 
Patterson K.D. and Peseran, B., 1992, The intertemporal elasticity of substitution in consumption in the U.S. and in the U.K., Review of Economics and Statistics 74, 573-584.

Rodrik, D., 1999, Where did all the growth go? External shocks, social conflict, and growth collapses, Journal of Economic Growth 4, 385-412.

Rodrik, D., Subramanian, A. and Trebbi, F., 2004, Institutions rule: The primacy of institutions over geography and integration in economic development, Journal of Economic Growth 9, 131-65.

Steger, T.M., 2000, Economic growth with subsistence consumption, Journal of Development Economics $62,343-361$.

Strulik, H., 2008a, Geography, health, and the pace of demo-economic development, Journal of Development Economics, forthcoming.

Strulik, H., 2008b, Social composition, Social conflict, and economic development, Economic Journal, forthcoming.

Sydsaeter, K., P. Hammond, A. Seierstad, and A. Strom, 2005, Title, Pearsons, Harlow.

Tornell, A., and Lane, P.R., 1999, The voracity effect, American Economic Review 89, 2246.

Zak, P.J. and Knack, S., 2001, Trust and Growth, Economic Journal 111, 295-321. 